Article

\title{
Differential Gene Expression Analysis of SoCBL Family Calcineurin B-like Proteins: Potential Involvement in Sugarcane Cold Stress
}

\author{
Bao-Qing Zhang ${ }^{1}$, Xiu-Peng Song ${ }^{1}$, Xiao-Qiu Zhang ${ }^{1}$, Yu-Xin Huang ${ }^{1}$, Yong-Jian Liang ${ }^{2}$, Shan Zhou ${ }^{1}$, \\ Cui-Fang Yang ${ }^{1}$, Li-Tao Yang ${ }^{2}$, Xing Huang ${ }^{1, *}$ and Yang-Rui Li ${ }^{1,2, * \mathbb{D}}$
}

1 Key Laboratory of Sugarcane Biotechnology and Genetic Improvement (Guangxi), Ministry of Agriculture and Rural Affairs/Guangxi Key Laboratory of Sugarcane Genetic Improvement, Sugarcane Research Institute, Guangxi Academy of Agricultural Sciences, Nanning 530007, China; zbqsxau@126.com (B.-Q.Z.); xiupengsong@163.com (X.-P.S.); zhangxiaoqiuxhd@163.com (X.-Q.Z.); huangyuxin13@163.com (Y.-X.H.); shan1268225@126.com (S.Z.); yj993@163.com (C.-F.Y.)

2 College of Agriculture, Guangxi University, Nanning 530005, China; Yongjianliang_605@163.com (Y.-J.L.); liyr@gxu.edu.cn (L.-T.Y.)

* Correspondence: shmilyx023@163.com (X.H.); liyr@gxaas.net (Y.-R.L.); Tel./Fax: +86-771-389-9033 (Y.-R.L.)

\section{check for}

updates

Citation: Zhang, B.-Q.; Song, X.-P.; Zhang, X.-Q.; Huang, Y.-X.; Liang,

Y.-J.; Zhou, S.; Yang, C.-F.; Yang, L.-T.; Huang, X.; Li, Y.-R. Differential Gene Expression Analysis of SoCBL Family Calcineurin B-like Proteins: Potential Involvement in Sugarcane Cold

Stress. Genes 2022, 13, 246.

https://doi.org/10.3390/ genes13020246

Academic Editor: Jean Molinier

Received: 3 December 2021

Accepted: 21 January 2022

Published: 27 January 2022

Publisher's Note: MDPI stays neutral with regard to jurisdictional claims in published maps and institutional affiliations.

Copyright: (C) 2022 by the authors. Licensee MDPI, Basel, Switzerland. This article is an open access article distributed under the terms and conditions of the Creative Commons Attribution (CC BY) license (https:/ / creativecommons.org/licenses/by/ $4.0 /)$.

\begin{abstract}
Sugarcan e is a major crop for sugar and biofuel production and is cultivated in tropical and subtropical areas worldwide. Sugarcane growth is constrained because of winter's low-temperature stress, and cold resistance is an important limitation in sugarcane growth enhancement. Therefore, in this study, we identified a gene involved in the low-temperature stress response of sugarcane. Calcineurin B-like (CBL) protein is a calcium signal receptor involved in the cold stress response. Five sugarcane CBL genes were cloned, sequenced, and named SoCBL1, SoCBL3, SoCBL5, SoCBL6, and SoCBL9. The protein sequences of these genes were analyzed. The calculated molecular weight of these proteins was $24.5,25.9,25.2,25.6$, and $26.3 \mathrm{kD}$, respectively. Subcellular localization analysis revealed that SoCBL1, SoCBL3, SoCBL6, and SoCBL9 were situated in the cytoplasm, while SoCBL5 was present in mitochondria. Secondary structure analysis showed that these five CBL proteins had similar secondary structures. Conserved domain analysis displayed that each sugarcane CBL protein contained three conserved EF domains. According to the self-expanding values of the phylogenetic tree, the CBL gene family was divided into four groups. The CBL1 and CBL9 genes were classified into one group, illustrating that these two genes might possess a similar function. The expression analysis of the SoCBL gene under low temperatures showed that SoCBL3 and SoCBL5 were affected significantly, while SoCBL1 and SoCBL9 were less affected. These results demonstrate that the CBL genes in sugarcane have similar characteristics and present differences in genetic diversity and gene expression response to low temperatures. Therefore, these genes might be novel candidates for fighting cold stress in sugarcane.
\end{abstract}

Keywords: cold stress; calcineurin B-like protein; gene expression evolutionary analysis; qRT-PCR; sugarcane

\section{Introduction}

Plants are constantly confronted with various abiotic stresses, such as drought, extreme temperatures, and salinity, during their growth. In order to adapt to environmental changes and self-protection, a complex signal transmission network system has been formed in the process of evolution to perceive and respond to environmental stress. Many stress-responsive genes receive these stress signals and notice their expression at specific times, prompting tissues to undergo physiological changes to adapt to the environment [1]. Among these changes, calcium signal transduction in plants is an essential signaling pathway for stress transmission by enhancing the calcium concentration in vivo in plants $[2,3]$. 
Thus far, three calcium signal sensors, including calmodulin (CaM), calcium-dependent protein kinase (CDPK), and calcineurin B-like protein (CBL), have been found in plant cells [4-7]. Signal transduction occurs between calcium signals and their interacting proteins to regulate the expression of downstream response genes, indicating that calcium signaling is a key regulatory pathway in the plant response to stress.

Calcineurin B-like (CBL) protein is a type of calcium signal receptor specific to plants. The core region of the plant CBL protein is relatively conserved, including four EF-hand motifs with the characteristic $\mathrm{Ca}^{2+}$ affinity and $\mathrm{Ca}^{2+}$ binding [8], but variations of EF-hand domain sequences occur in different CBLs [9]. Each CBL protein interacts with a downstream kinase harboring 26 serine/threonine, forming a CBL-interacting protein kinase (CIPKs) [10]. Subsequently, the activated CIPKs rapidly phosphorylate the downstream signaling molecules to build an entire signaling network to transmit calcium signals [11]. CBL1 plays an essential role in various abiotic stress pathways, while CBL4/SOS3 is involved in mediating ion tolerance [11,12].

At present, several studies have confirmed that CBL is involved in the external environment's effect on plants. Indeed, in Arabidopsis, AtCBL1 is an upstream regulator of stress response genes [13]. AtCBL9 overexpression produced enhanced tolerance to drought [14]. AtCBL9 mutant plants became hypersensitive to ABA at the early developmental stages, whereas it attenuated the response to drought and salinity. On the contrary, AtCBL9 overexpression increased stress tolerance, indicating that CBL is involved in the plant response and the regulation of stress signals [15]. Rice OsCBL1 and OsCBL3 respond to $\mathrm{ABA}, \mathrm{NaCl}$, and low-temperature stress [16]. The pea PsCBL gene was involved in responsiveness to salt/alkali, drought, and low-temperature stress [17]. The expression of SiCBL1, SiCBL3, and SiCBL5 in millet was increased under drought and salt stress [18]. To date, there have been few reports on $C B L$ genes in sugarcane [19-22]. Farani et al. [19] characterized the protein-protein interactions of ScCIPK8 with six CBL proteins (ScCBL1, ScCBL2, ScCBL3, ScCBL6, ScCBL9, and ScCBL10). Ling et al. [20] found that SsCBL1 and SsCBL6 play important regulatory roles in response to a variety of stresses (low potassium, drought, and salt). According to datasets of the transcription sequencing of sugarcane genes under abiotic stress, Ling et al. [21] cloned a calcineurin B-like gene named SsCBL4 (GenBank No. KY674 987.1) from sugarcane root. Su et al. [22] obtained three CBL genes (GenBank accession nos. KX013374, KX013375, and KX013376) from sugarcane variety ROC22. These ScCBL genes were constitutively expressed in the sugarcane bud, stem pith, leaf, meristem, and stem skin, and they showed different expression patterns in response to stimulation with phytohormones and various abiotic stresses.

In order to understand the relationship between $C B L$ genes and low-temperature stress in sugarcane, the mRNAs of five sugarcane CBL genes were cloned and sequenced. Bioinformatics and genetic diversity analyses of the translated protein sequences were performed. Real-time PCR was used to study the expression pattern of these genes in response to low temperatures. A low temperature has a profound effect on increasing the expression of $C B L$ genes. The results might provide an insight into the roles of $C B L$ genes in low-temperature resistance in sugarcane.

\section{Materials and Methods}

\subsection{Plant Material and Growth Conditions}

The cold-resistant sugarcane cultivar GT28 and the cold-susceptible cultivar YL6 used in this experiment were supplied by the Sugarcane Research Institute, Guangxi University.

In a greenhouse, the single-bud seedcane sets were planted on a mixed substrate of soil and sand. When the plants reached three leaves, those with consistent growth were selected and transplanted for soil culture in pots in a randomized design. The pots were $300 \mathrm{~mm}$ in diameter and $350 \mathrm{~mm}$ in height and filled with $17.5 \mathrm{~kg}$ culture medium (soil-organic fertilizer-sand $=70-20-10$ in weight). Each pot had 2-3 plants. In order to enhance permeability, holes were punched in the bottom of the pots. The plants were managed routinely. After 10 months of normal growth, when the plants were at the sugar- 
accumulating stage, low-temperature treatment was applied. For treatment, the plants were divided into two groups. The first group was grown normally, as the control, with a temperature of $25^{\circ} \mathrm{C}$, a light intensity of $250-300 \mu \mathrm{mol} / \mathrm{m}^{2} \cdot \mathrm{s}$, a $12 \mathrm{~h}$ photoperiod, and relative humidity of $60-70 \%$. The second group was treated with a low-temperature set at 0-4 ${ }^{\circ} \mathrm{C}$, light intensity at $250-300 \mu \mathrm{mol} / \mathrm{m}^{2} \cdot \mathrm{s}, 12 \mathrm{~h}$ photoperiod, and relative humidity at 60-70\%. After 2, 4, 6, and 8 days of low-temperature stress, the leaf and stem tip samples were collected at 8:00 am, quick-frozen in liquid nitrogen, and stored at $-80{ }^{\circ} \mathrm{C}$.

\section{2. cDNA First-Strand Synthesis}

The shoots were frozen in liquid nitrogen and ground into powder. Total RNA was extracted using Trizol (Invitrogen, Gaithersburg, MD, USA) as described by the manufacturer. RNA concentration and integrity were determined using NanoDrop (Thermo Fisher, Saint Luis, MO, USA) and agarose gel electrophoresis, respectively. The first strand of cDNA for gene cloning was synthesized using the M-MLV cDNA first-strand synthesis kit (Takara, DaLian, China) according to the protocol provided by the manufacturer. Then, the cDNA was diluted to the concentration of $100 \mu \mathrm{g} / \mu \mathrm{L}$ for further gene cloning PCR. Finally, cDNA synthesis for qRT-PCR was carried out using the PrimeScript RT Reagent Kit with gDNA Eraser (Takara, DaLian, China) according to the provided protocol.

\subsection{PCR Primer Design and Amplification Conditions}

In order to find the conserved sequence for primer design, highly homologous nucleic acid sequences of $C B L$ genes were selected for the alignment analysis using DAMAN software. The forward and reverse primers of the target gene were designed for cloning (Table 1$)$. The PCR reaction mixture $(25 \mu \mathrm{L})$ was as follows: mixture cDNA template $1 \mu \mathrm{L}, 10 \times$ buffer $2 \mu \mathrm{L}$, forward primer $(10 \mathrm{mM}) 1 \mu \mathrm{L}$, reverse primer $(10 \mathrm{mM}) 1 \mu \mathrm{L}$, Taq DNA polymerase $(200 \mathrm{U} / \mu \mathrm{L}) 0.16 \mu \mathrm{L}$, dNTPs $(10 \mathrm{mM}) 0.4 \mu \mathrm{L}$, and $\mathrm{ddH}_{2} \mathrm{O} 19.44 \mu \mathrm{L}$. PCR reaction was performed for 35 cycles of denaturation, annealing, and elongation at $95{ }^{\circ} \mathrm{C}$ for $40 \mathrm{~s}, 55^{\circ} \mathrm{C}$ for $50 \mathrm{~s}$, and $72{ }^{\circ} \mathrm{C}$ for $2 \mathrm{~min}$. After the reaction, $4 \mu \mathrm{L}$ of PCR products was validated by electrophoresis on $1.0 \%$ agarose gel. The PCR products were gel-purified and cloned into a pMD18-T vector as described by the manufacturer (Takara, DaLian, China). The clone was sequenced using the ABI 3730XL genetic analyzer (Thermo Fisher, Saint Luis, MO, USA).

Table 1. PCR primers used for gene cloning analysis.

\begin{tabular}{ccc}
\hline Primer & Sequence $\left(\mathbf{5}^{\prime} \mathbf{- 3}^{\prime} \mathbf{)}\right.$ & Size of Fragment (bp) \\
\hline CBL1-F & ATGGGGTGCTTCCATTCCACGGCGA & 6 \\
CBL1-R & TCACGTGACGAGATCGTC(C/G) ACTTC & 642 \\
CBL3-F & ATG(T/G)TGCAGTGCCTGGA(T/C) GG & 678 \\
CBL3-R & TCAG(T/G)TATCATCGAC(T/C)TGAGA & \multirow{2}{*}{657} \\
CBL5-F & ATGGGCTGTCTGCAAACAAAGCACG & \multirow{2}{*}{672} \\
CBL5-R & TTAGACAGCCATGTCTGTTTC & \multirow{2}{*}{693} \\
CBL6-F & ATGGTGGACTT(T/C) GTTCGACGGCT & \\
CBL6-R & TCACGCATCCTCTACTTG(A/C) GAGTTG & \\
CBL9-F & ATGGG(A/G) TGCTTCCATTCCACGGC & \\
\hline
\end{tabular}

\subsection{Sequence Analysis and Prediction}

The nucleotide sequences of the $C B L 1, C B L 3, C B L 5, C B L 6$, and $C B L 9$ genes in sugarcane were analyzed via various analytical software programs and tools. BioXM 2.6 was used to predict the gene-encoded amino acid sequence. NCBI online analysis software was used for gene homology analysis compared to other species. The protein molecular weight and isoelectric point were analyzed using online software (http:/ / isoelectric.ovh.org/, accessed on 3 December 2021). Protein subcellular localization was analyzed using the WoLF PSORT online software. SOSUI signal software was used for prediction of the signal 
peptide. Protein secondary structure was predicted by the SOPMA software. The protein motif was analyzed using Motif Scan online software. MEGA 4.0 software was used to construct a phylogenetic tree for each gene-encoded amino acid sequence compared to other species.

\subsection{Real-Time Quantitative PCR for Gene Expression Analysis}

Specific primers for real-time PCR were designed based on the full-length cDNA sequences of $C B L 1, C B L 3, C B L 5, C B L 6$, and CBL9 genes (Table 2). The sugarcane glyceraldehyde 3-phosphate dehydrogenase (GAPDH) gene (EF189713) was used as the reference gene. The real-time PCR reaction was performed on a Light Cycler 480II (Roche, Switzerland) real-time PCR instrument, and the data were analyzed using qBASE plus software. The qRT-RCR reaction mixture $(20 \mu \mathrm{L})$ included SYBR ${ }^{\circledR}$ PremixExTaqTMII $(2 \times) 10 \mu \mathrm{L}$, forward primer $(10 \mu \mathrm{M}) 0.8 \mu \mathrm{L}$, reverse primer $(10 \mu \mathrm{M}) 0.8 \mu \mathrm{L}$, cDNA template of each sample $(50 \mathrm{ng} / \mu \mathrm{L}) 2.0 \mu \mathrm{L}$, $\mathrm{ddH}_{2} \mathrm{O} 6.4 \mu \mathrm{L}$. The qRT-RCR reaction procedure was as follows: pre-incubation 1 cycle at $95^{\circ} \mathrm{C}$ for $30 \mathrm{~s}$, amplification 45 cycles at $95^{\circ} \mathrm{C}$ for $5 \mathrm{~s}$ and $60{ }^{\circ} \mathrm{C}$ for $20 \mathrm{~s}$, melting curve 1 cycle at $95^{\circ} \mathrm{C}$ for $1 \mathrm{~s}$ and $65^{\circ} \mathrm{C}$ for $15 \mathrm{~s}, 95^{\circ} \mathrm{C}$ continuous, and cooling at $40{ }^{\circ} \mathrm{C}$ for $30 \mathrm{~s}$. The relative expression was calculated by the $2^{-\Delta \Delta \mathrm{Ct}}$ method with three biological replicates.

Table 2. Primers used for real-time PCR analysis.

\begin{tabular}{clc}
\hline Primer & \multicolumn{1}{c}{ Sequence $\mathbf{( 5}^{\prime} \mathbf{- 3}^{\prime} \mathbf{)}$} & Size of Fragment (bp) \\
\hline GAPDH-F & AAGGGTGGTGCCAAGAAGG & 145 \\
GAPDH-R & CAAGGGGAGCAAGGCAGTT & 131 \\
CBL1-F & TATGGATGGCACAGGGTTTATT & 123 \\
CBL1-R & CAGCGTCCGAAAATGTCTTATC & \multirow{2}{*}{98} \\
CBL3-F & AGCAAGAAGGAGAGCCTGTTC & 172 \\
CBL3-R & AAGGGGAGCATTAGGATGAAAT & 131 \\
CBL5-F & ACACAAAAGGTGATGGGAAGAT & \multirow{2}{*}{ CBL5-R } \\
CBL6-F & CTTGAGGTAGGGAAGGGTCATA & \\
CBL6-R & GTGGTTGATGATGGCTTGATTA & \\
CBL9-F & CACTTGGATGGAACACAGAAAG & \\
CBL9-R & TATGGATGGCACAGGGTTTATT & \\
\hline
\end{tabular}

\subsection{Statistical Analysis}

The data were analyzed using SPSS 15.0 software, and the significant difference between treatments was tested with Duncan's new multiple range method $(P \leq 0.05)$.

\section{Results}

\subsection{Total RNA and cDNA Quality of Sugarcane Leaves}

The total RNA in sugarcane leaves was extracted using Trizol, and the concentration and purity of the total RNA were detected by $1.0 \%$ agarose gel electrophoresis and UV spectrophotometry (Figure 1A). The results showed that the OD260/280 value was between 1.85 and 1.95, and the OD260/230 was between 2.0 and 2.2, indicating that the purity and quality of the extracted RNA were high. The RNA was used to synthesize cDNA using a reverse transcription kit, and the size of the cDNA products was between 100 and $2000 \mathrm{bp}$, illustrating that the reverse transcription quality was good (Figure 1B). Therefore, the total RNA and cDNA obtained in the experiment were good enough for the subsequent experiments. 

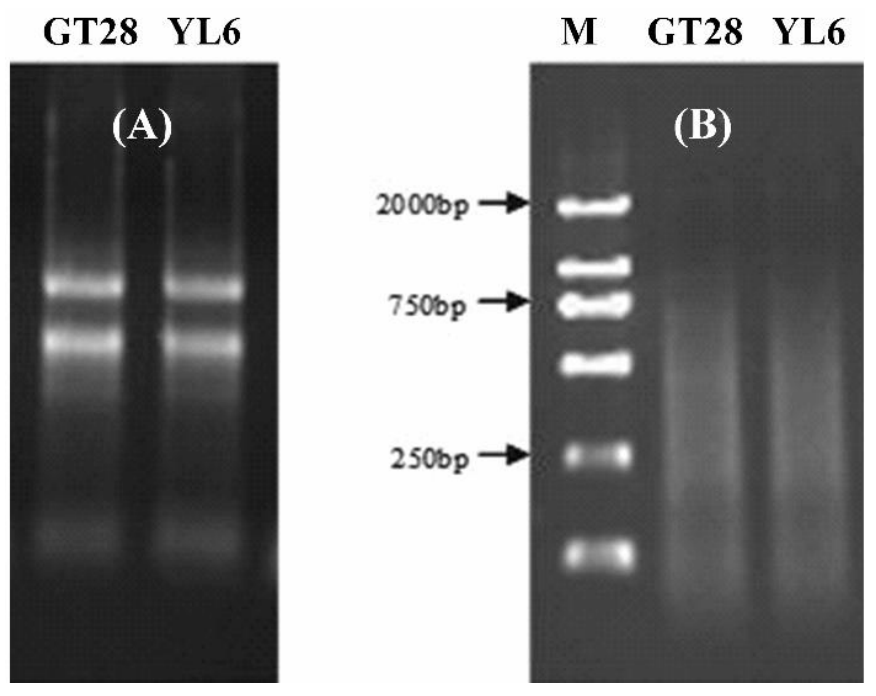

Figure 1. The quality of total RNA and cDNA from leaves of sugarcane cultivars GT28 and YL6. (A) The total RNA was detected by $1.0 \%$ gel agarose gel electrophoresis. (B) The size of the cDNA products was between 100 and $2000 \mathrm{bp}$. M, molecular weight marker.

\subsection{Cloning and Sequencing of Sugarcane SoCBL Genes}

According to the literature, the $C B L$ genes are related to cold tolerance $[1,13,17,23,24]$. Therefore, from the NCBI database, we referred to the $C B L$ gene nucleic acid sequences of sorghum and maize to design the upstream and downstream degenerate primers for $C B L 1$, CBL3, CBL5, CBL6, and CBL9, respectively. Then, using CDNA as the template and the upstream and downstream primers of the above five genes, the fragments of $642,678,657$, 672, and 693 bp were amplified, respectively (Figure 2), and they were recovered, cloned, and sequenced. After comparison, it was found that the cDNA lengths were the same as those of $C B L 1, C B L 3, C B L 5, C B L 6$, and CBL9. Therefore, they were named SoCBL1, SoCBL3, SoCBL5, SoCBL6, and SoCBL9, respectively, and the NCBI gene registration numbers were KC800815, KC800816, KC800817, KC800818, and KC800819, respectively.
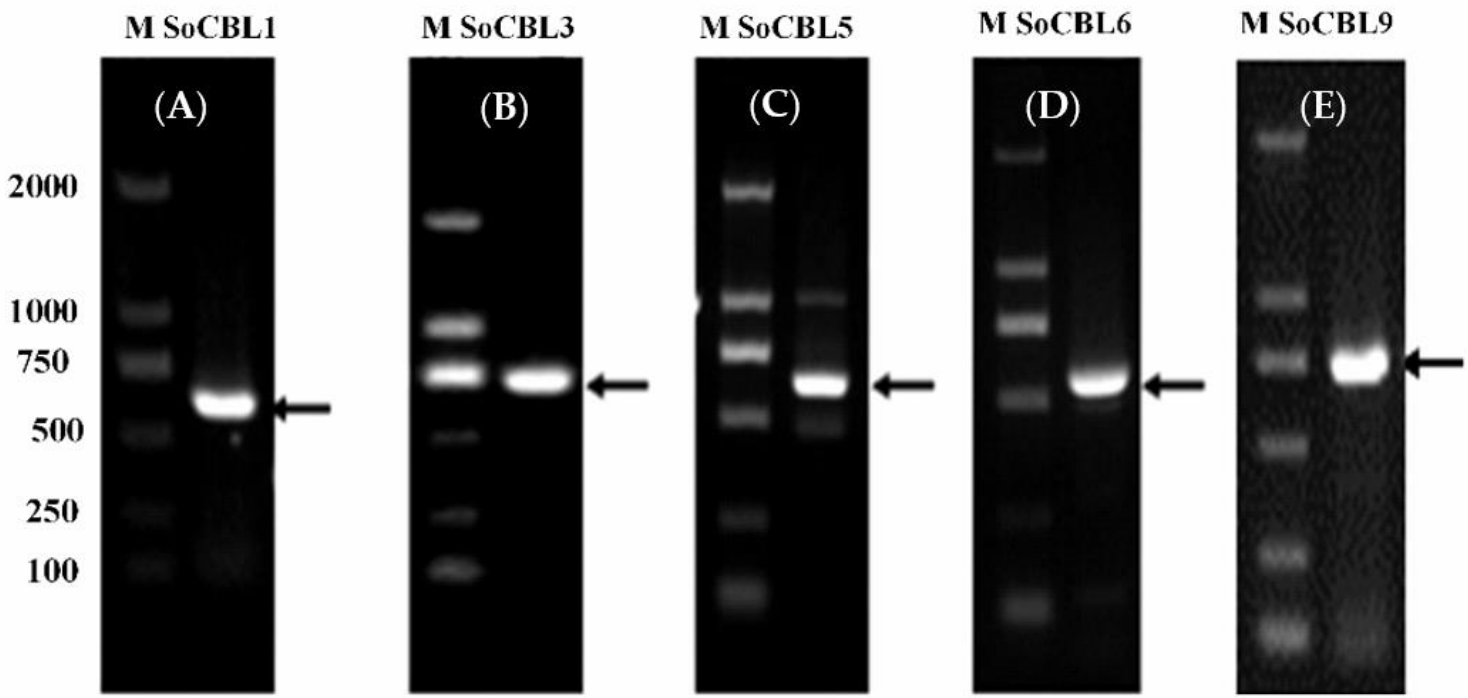

Figure 2. PCR product analysis of the five SoCBL genes (A): SoCBL1; (B): SoCBL3; (C): SoCBL5; (D): SoCBL6; (E): SoCBL9 in sugarcane. $\mathrm{M}$, molecular weight marker.

\subsection{Bioinformatics Analysis of Sugarcane SoCBL}

Bioinformatics analyses of the amino acid sequences of sugarcane SoCBL proteins (SoCBL1, SoCBL3, SoCBL5, SoCBL6, and SoCBL9) were performed (Figure 3). 
Section 1
(1) 1
10
20
30
40
55

CBL1 (1) - - - - - - - - MGCFHST AKRQH P GY E D P VHLASQTAF S VS EVEALFEL

CBL3 (1) - -MLQCLDGVRQLLAVLLRCCDVELK-QPRGLEDPQVLARETVFSVSEVEALYEL

CBL5 (1) - - - - - - - - MGCLQTKHARRS PHLLAREAVALAAETSETVSEVEALHEL

CBL6 (1) - - - -MVDFVRRLASALLKCCDLDIPNRPKGLEDPERLARETVENVNEIEALYEL

CBL9 (1) MTMITNSSSVPGDPLEIMGCFHSTAKRQHPGYEDPVHLASQTAFSVSEVEALEEL

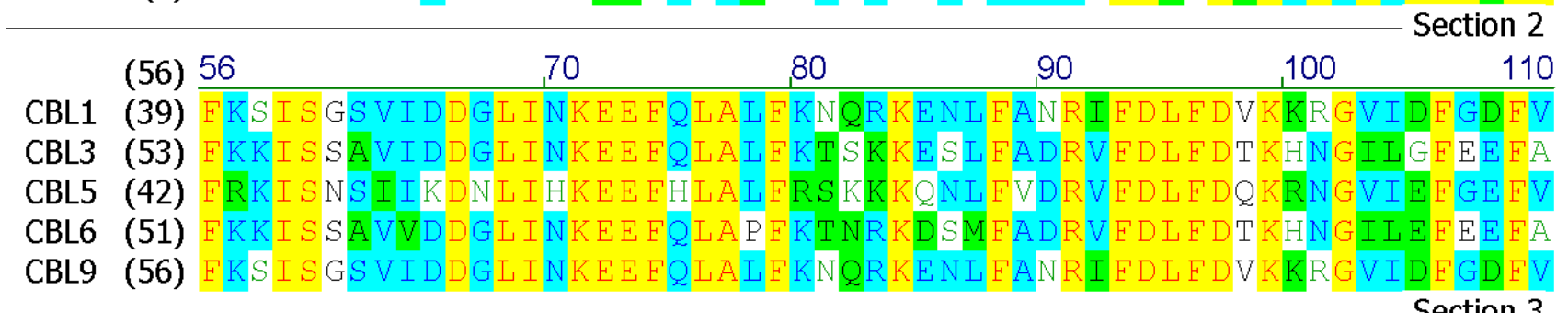

Section 3
(111) 111
120
130
140
150
165

CBL1 (94) RALNVFH PNI PMEEKI DESFKLYDMD GTGFIERKEVKQML I AL L GESEMRLSDEI

CBL3 (108) RALSVFH PNA P L D DK I DF S FQL Y D L KQQ GY I ERQEVKQMVVA T LA E S GMNL S D E I

CBL5 (97) RSLSVEHPDTPEEQKVAFAFKLYDLRQTGFIERHELKEMVLALLDESDLDIASDA

CBL6 (106) RALSVFH P SA P I D I I FAFKLY DLKQQ GF I EKQEVKQMVVAT LAES GMNLSDDI

CBL9 (111) RALNVFH PNI PMEEKI DFS FKLY DMD GTGFI ERKEVKQML I AL L GES EMRLSDE I

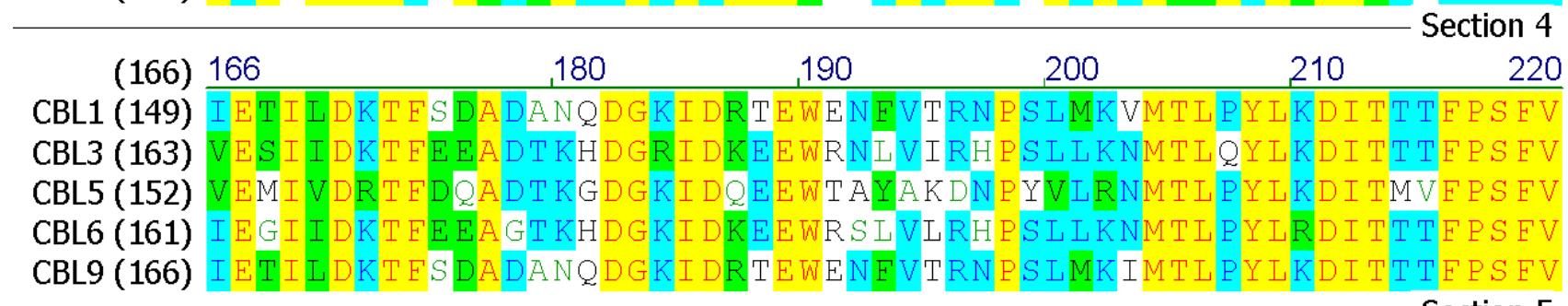

Section 5

(221) 221

232

CBL1 (204) FNSEVDDLVT--

CBL3 (218) FHSQVDDN-- -

CBL5 (207) MHSE ISET DMAV

CBL6 (216) FNSQVEDA-- -

CBL9 (221) FNSEVDDLVT--

Figure 3. Predicted amino acid sequences of the SoCBL proteins in sugarcane.

The protein molecular weights of the five proteins were 24.5, 25.9, 25.2, 25.6, and $26.3 \mathrm{kD}$, respectively, and their corresponding isoelectric points were 4.6, 4.6, 5.0, 4.7, and 4.5 , respectively (Table 3 ).

Table 3. Identification of the five SoCBL proteins in sugarcane.

\begin{tabular}{cccc}
\hline Protein & Accession Number & MW & pI \\
\hline SoCBL1 & AGO81718.1 & $24.5 \mathrm{kD}$ & 4.6 \\
SoCBL3 & AGO81719.1 & $25.9 \mathrm{kD}$ & 4.6 \\
SoCBL5 & AGO81720.1 & $25.2 \mathrm{kD}$ & 5.0 \\
SoCBL6 & AGO81721.1 & $25.6 \mathrm{kD}$ & 4.7 \\
SoCBL9 & AGO81722.1 & $26.3 \mathrm{kD}$ & 4.5 \\
\hline
\end{tabular}

In addition, the subcellular localization analysis of the SoCBL proteins using online software revealed that SoCBL1, SoCBL3, SoCBL6, and SoCBL9 were mainly located in the cytoplasm, while SoCBL5 was mainly located in mitochondria. No signal peptide was 
detected in SoCBL1, SoCBL5, SoCBL6, and SoCBL9. The sequence of SoCBL3 contained a signal peptide (MLQCLDGVRQLLAVLLRCCD) located at the C-terminus. No transmembrane motifs were aligned in any of the five proteins using TMpred. In order to further understand the structure and function of the SoCBL proteins, prediction of the protein secondary structure was performed using SOPMA. The analysis result showed that, even with different sequences, the amount and ratio of each putative secondary structure were relatively similar (Table 4 ).

Table 4. Putative functional domain analysis of amino acid sequences encoded by five SoCBL proteins in sugarcane.

\begin{tabular}{|c|c|c|c|c|c|c|}
\hline Protein & $\begin{array}{c}\text { Casein Kinase II } \\
\text { Phosphorylation } \\
\text { Site }\end{array}$ & N-Myristoylation Site & Phosphorylation Site & N-Glycosylation Site & $\begin{array}{c}\text { CAMP- and } \\
\text { cGMP-Dependent } \\
\text { Protein Kinase } \\
\text { Phosphorylation } \\
\text { Site }\end{array}$ & $\begin{array}{c}\text { EF } \\
\text { Calcium-Binding } \\
\text { Domain }\end{array}$ \\
\hline SoCBL1 & $\begin{array}{c}28 \sim 31,45 \sim 48 \\
151 \sim 154,156 \sim 159, \\
171 \sim 174,206 \sim 209 \\
42 \sim 45,79 \sim 82\end{array}$ & $2 \sim 7$ & 7 9, 112 114 & & & $\begin{array}{c}161 \sim 173,67 \sim 102, \\
104 \sim 139,\end{array}$ \\
\hline SoCBL3 & $\begin{array}{c}150 \sim 153,165 \sim 168, \\
170 \sim 173,176 \sim 179, \\
220 \sim 223\end{array}$ & $155 \sim 160$ & & 157 160, 200 203 & $54 \sim 57,80 \sim 83$ & $\begin{array}{c}79 \sim 114,116 \sim 151, \\
160 \sim 195\end{array}$ \\
\hline SoCBL5 & $\begin{array}{c}31 \sim 34,106 \sim 109 \\
143 \sim 146,165 \sim 168 \\
212 \sim 215\end{array}$ & $2 \sim 7$ & $67 \sim 69$ & $189 \sim 192$ & $43 \sim 46$ & $\begin{array}{c}70 \sim 105,107 \sim 142 \\
151 \sim 186\end{array}$ \\
\hline SoCBL6 & $\begin{array}{l}148 \sim 151,168 \sim 171 \\
174 \sim 177,218 \sim 221\end{array}$ & $153 \sim 158$ & $76 \sim 78$ & $155 \sim 158,198 \sim 201$ & $52 \sim 55,78 \sim 81$ & $\begin{array}{c}\text { 79 114, } 116 \sim 151, \\
160 \sim 195\end{array}$ \\
\hline SoCBL9 & $\begin{array}{c}45 \sim 48,62 \sim 65, \\
168 \sim 171,173 \sim 176, \\
188 \sim 191,223 \sim 226\end{array}$ & $19 \sim 24$ & $24 \sim 26,129 \sim 131$ & $6 \sim 9$ & & $\begin{array}{c}84 \sim 119,121 \sim 156 \\
165 \sim 200\end{array}$ \\
\hline
\end{tabular}

In order to identify the regulation of protein expression, we performed some posttranslation modification site analyses on the SoCBL proteins (Table 5). The numbers of putative casein kinase II phosphorylation sites in SoCBL1, SoCBL3, SoCBL5, SoCBL6, and SoCBL9 were six, seven, five, four, and four, respectively. There was one putative $\mathrm{N}$-myristoylation site in each SoCBL protein. SoCBL1 and SoCBL5 had similar putative sites in N-myristoylation, while SoCBL3 shared alike putative N-myristoylation sites and cAMP- and cGMP-dependent protein kinase phosphorylation putative sites with SoCBL6. In the EF calcium-binding domain and EF domain analyses, all SoCBL proteins contained the same number and similar location of these two putative domains.

Table 5. Putative secondary structure of the five SoCBL proteins in sugarcane.

\begin{tabular}{ccccc}
\hline Protein & $\begin{array}{c}\text { Number of } \\
\boldsymbol{\alpha} \text {-Helices }\end{array}$ & $\begin{array}{c}\text { Number of } \\
\text { Extended Strands }\end{array}$ & $\begin{array}{c}\text { Number of } \\
\boldsymbol{\beta} \text {-Turns }\end{array}$ & $\begin{array}{c}\text { Number of } \\
\text { Random Coils }\end{array}$ \\
\hline SoCBL1 & $106(49.8 \%)$ & $16(7.5 \%)$ & $14(6.6 \%)$ & $77(36.2 \%)$ \\
SoCBL3 & $126(56.0 \%)$ & $13(5.8 \%)$ & $18(8.9 \%)$ & $68(30.2 \%)$ \\
SoCBL5 & $110(50.5 \%)$ & $23(10.6 \%)$ & $14(7.2 \%)$ & $71(32.7 \%)$ \\
SoCBL6 & $121(54.3 \%)$ & $13(5.8 \%)$ & $16(7.2 \%)$ & $73(32.7 \%)$ \\
SoCBL9 & $118(51.3 \%)$ & $19(8.3 \%)$ & $16(7.0 \%)$ & $77(33.5 \%)$ \\
\hline
\end{tabular}

\subsection{Phylogenetic Analysis of Sugarcane SoCBL}

In order to investigate the evolutionary relationship of the sugarcane CBL protein family, phylogenetic analysis of the five sugarcane CBL protein sequences was performed. Twenty-four CBL proteins from different plants were retrieved from the GenBank database. All the protein sequences were aligned and trimmed. The resulting multiple sequence alignment (MSA) was used for phylogenetic analysis. The analysis showed that the CBL protein family was divided into four main clades (Figure 4). 


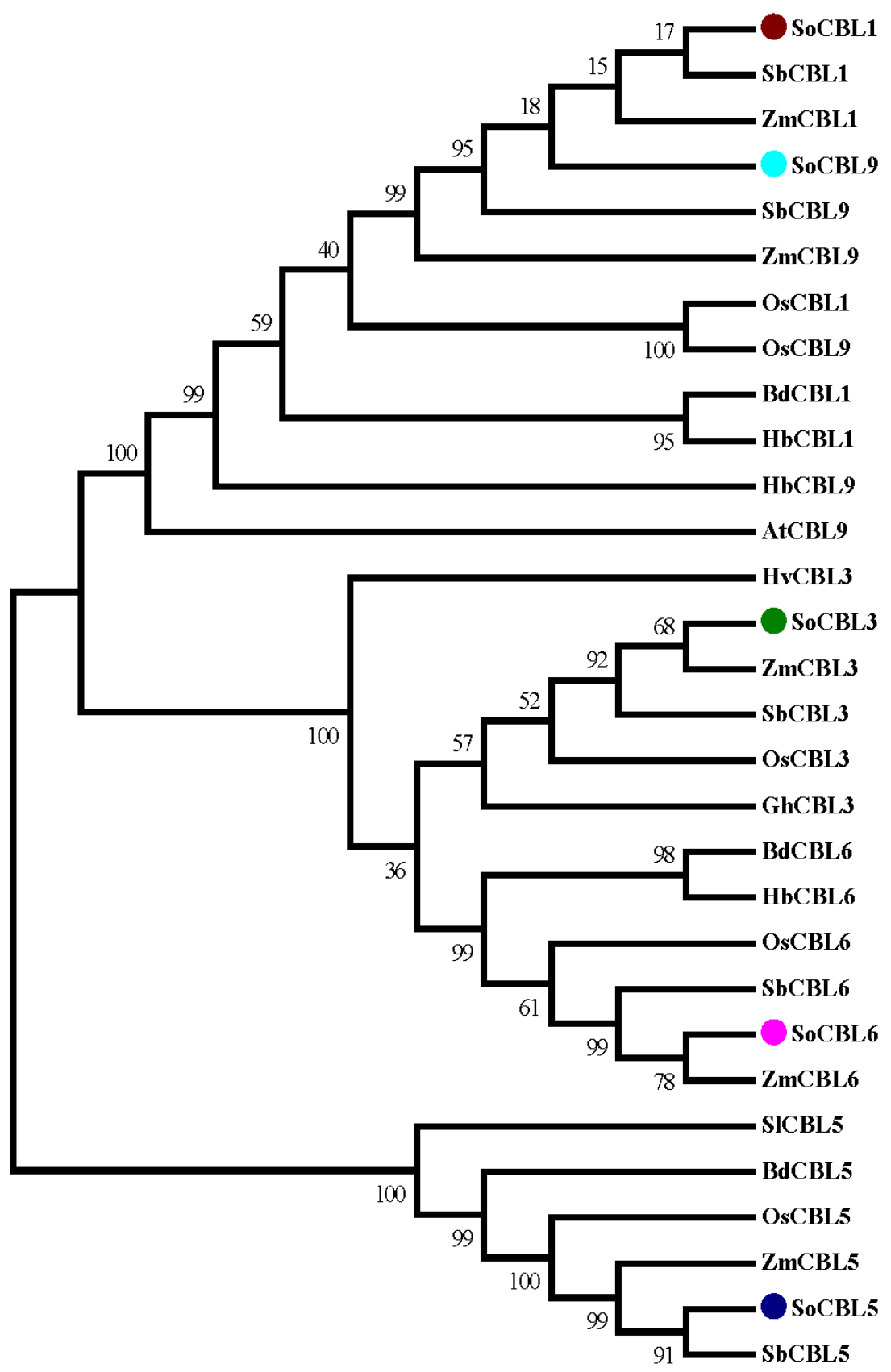

Figure 4. Amino acid sequence homology analysis of the SoCBL proteins from sugarcane compared with the CBL proteins from other plant species. SoCBL1, Saccharum officenarum; SbCBL1, Sorghum bicolor XP_002467472.1; ZmCBL1, Zea mays NP_001130480.1; OsCBL1 Oryza sativa Q7XC27.2; BdCBL1, Brachypodium distachyon XP_003574350.1; HbCBL1, Hordeum brevisubulatum AER42616.1; SoCBL3, Saccharum officenarum; SbCBL3, Sorghum bicolor XP_002442450.1; ZmCBL3, Zea mays NP_001131294.1; OsCBL3, Oryza sativa EEC69608.1; HvCBL3, Hordeum vulgare BAJ86631.1; GhCBL3, Gossypium hirsutum ABW06390.1; SoCBL5, Saccharum officenarum; SbCBL5, Sorghum bicolor ACQ83549.1; ZmCBL5, Zea mays DAA58834.1; OsCBL5, Oryza sativa BAD53426.1; BdCBL5, Brachypodium distachyon XP_003568025.1; SlCBL5, Solanum lycopersicum NP_001234705.1; SoCBL6, Saccharum officenarum; BdCBL6, Brachypodium distachyon XP_003563139.1; OsCBL6, Oryza sativa NP_001066223.1; ZmCBL6, Zea mays NP_001151206.1; SbCBL6, Sorghum bicolor XP_002442860.1; HbCBL6, Hordeum brevisubulatum AER42617.1; SoCBL9, Saccharum officenarum; ZmCBL9, Zea mays NP_001151319.1; OsCBL9, Oryza sativa Q7XC27.2; HbCBL9, Hordeum brevisubulatum AFD23460.1; AtCBL9, Arabidopsis thaliana NP_199521.1; SbCBL9, Sorghum bicolor XP_002467472.1. 
All the sequences of CBL1 and CBL9 were clustered into one clade, indicating that these two members have high sequence identity. Clade II contained all the CBL6 proteins of all the species with strong support (bootstrap percentages, $\mathrm{BP}=100$ ). Clade III comprised all the CBL3 proteins from all the species $(\mathrm{BP}=100)$. All the $C B L 5$ proteins were supported in clade IV but with lower bootstrap percentages $(\mathrm{BP}=50)$. Clades II and IV were the nodes with strong support $(\mathrm{BP}=100)$, demonstrating that CBL3 and CBL6 are genetically similar. Each of the same types of genes was clustered into different clades, indicating that different clades of the CBL protein family may present different functions. Within the main clade, the sugarcane (Saccharum officinarum, So) proteins were always clustered with the proteins from sorghum (Sorghum bicolor, $\mathrm{Sb}$ ) and maize (Zea mays, $\mathrm{Zm}$ ) (Figure 4). The CBL proteins from rice (Oryza sativa, Os) were correlated more to sugarcane than those from brome (Brachypodium distachyon, $\mathrm{Bd}$ ) and Hordeum brevisubulatum in sequence diversity.

\subsection{Change in Expression of SoCBL Genes in Response to Low-Temperature Stress}

In order to understand the relationship of low-temperature stress with SoCBL gene expression, the relative change in mRNA accumulation upon exposure to $4{ }^{\circ} \mathrm{C}$ for $2,4,6$, and 8 days was measured.

The results showed that the expression levels and trends of SoCBL1 and SoCBL9 genes were consistent in the cold-resistant cultivar GT28 and the cold-susceptible cultivar YL6 under low-temperature stress. The relative expression level of SoCBL1, SoCBL5, SoCBL6, and SoCBL9 increased, while SoCBL3 showed almost no change from 2 to 6 days of lowtemperature stress in the cold-resistant cultivar GT28. For the cold-susceptible cultivar YL6, however, the highest expression of these genes was found in the control, except for SoCBL3. After 2 days of low-temperature stress, the expression of SoCBL3 and SoCBL5 declined rapidly, and then showed a steady decline, and reached the lowest level at 8 days in cold-susceptible cultivar YL6 (Figure 5).

SoCBL1

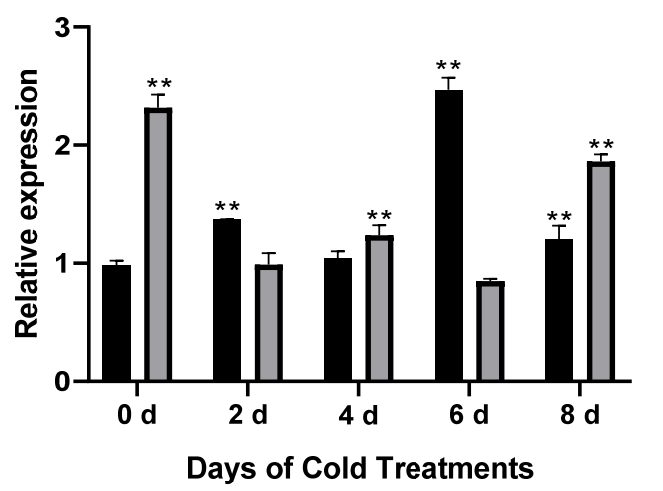

SoCBL5

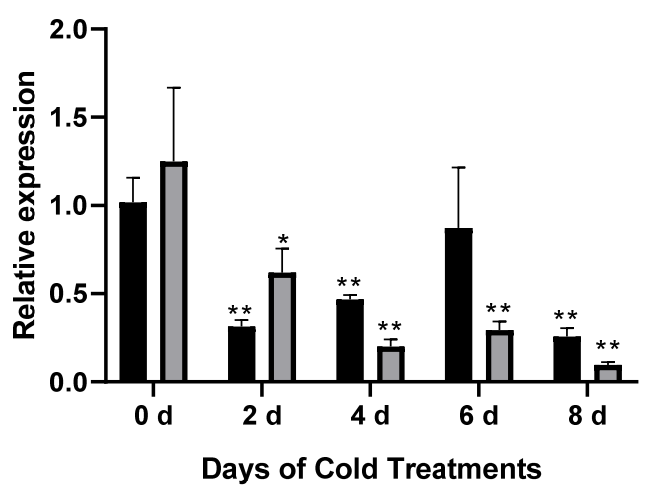

SoCBL3

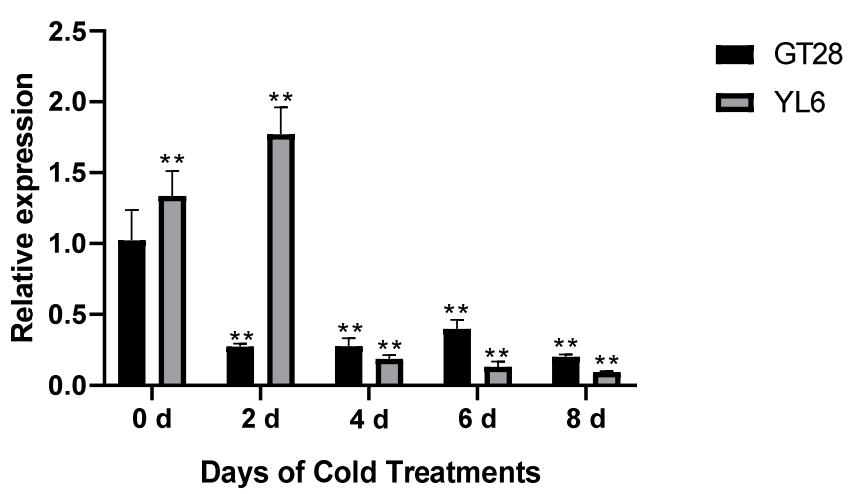

SoCBL6
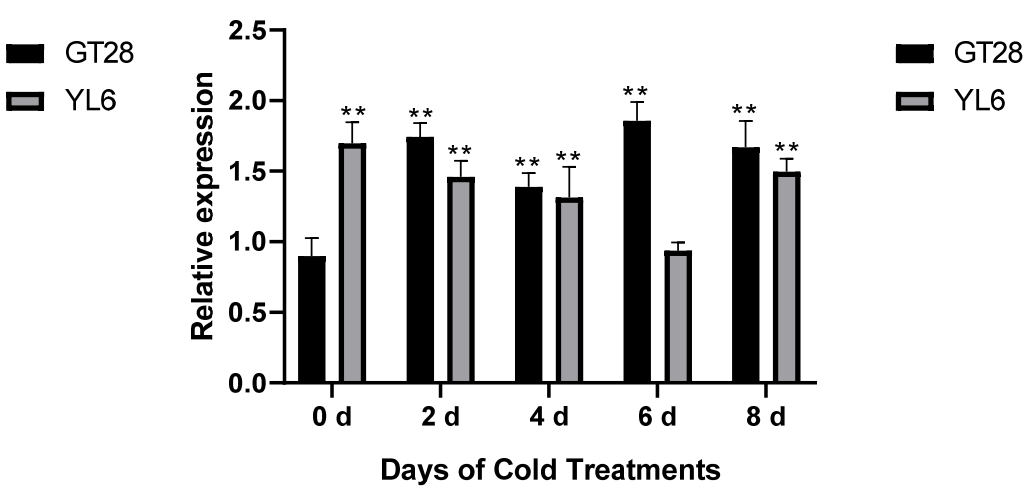

Figure 5. Cont. 
SoCBL9

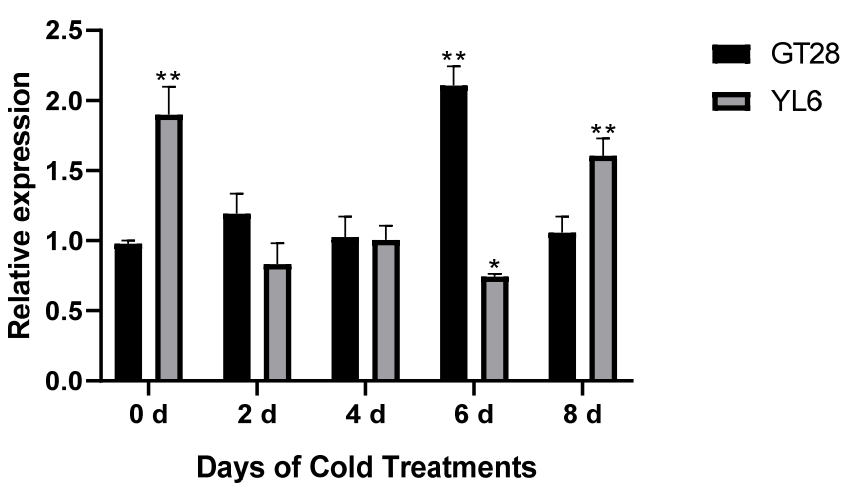

Figure 5. Expression analysis of the SoCBL genes in the leaves of sugarcane cultivars GT28 (coldresistant) and YL6 (cold-susceptible) under low-temperature stress. All the tested results were obtained from 3 biological replicates and statistical analysis was applied via Student's $t$-tests in GraphPad Prism 8.0 software; $p<0.05$ for significant difference ${ }^{*}$ ) and $p<0.01$ for highly significant difference $\left.{ }^{* *}\right)$.

In addition, the relative expression stability of these five SoCBL genes under lowtemperature stress was analyzed using qBASE plus software, and the results (Figure 6) indicated that the higher the expression value, the more affected the plant was under low-temperature stress.
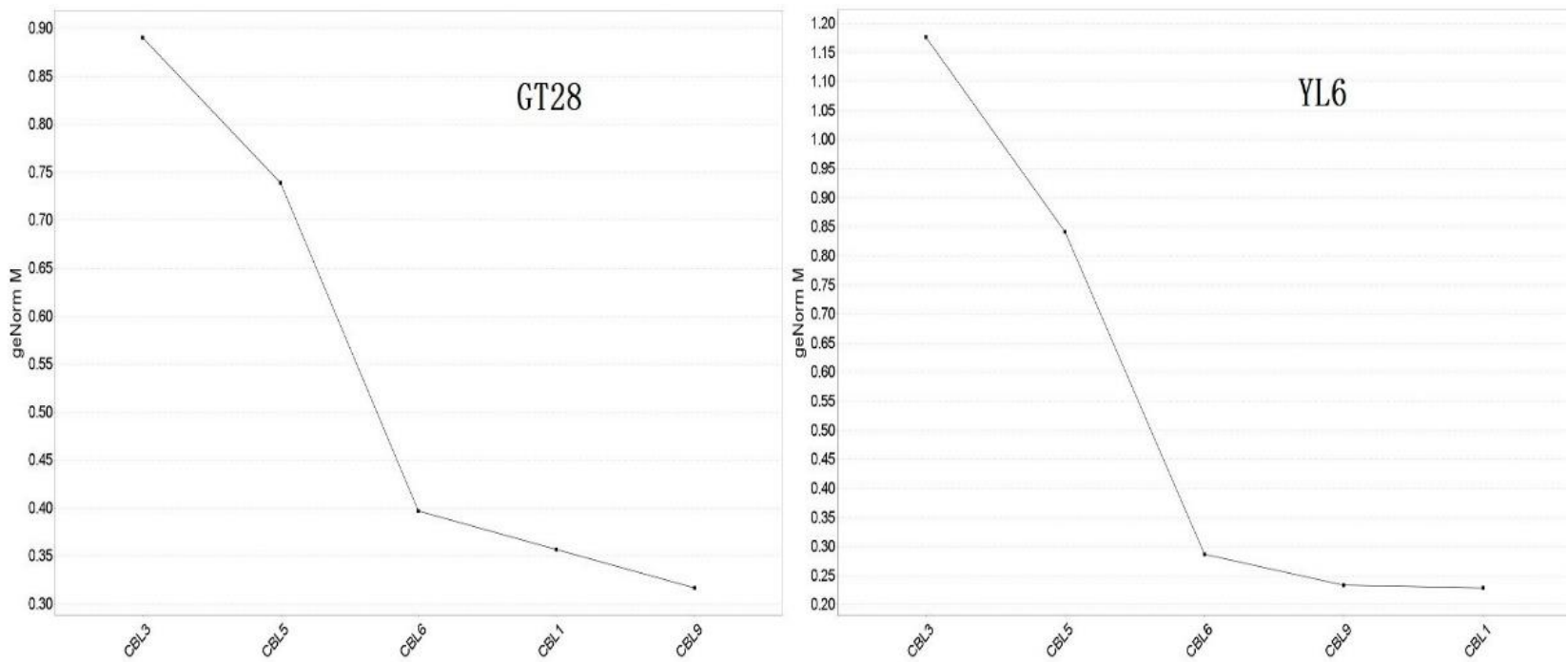

Figure 6. Average expression stability of sugarcane SoCBL genes under low-temperature stress.

All five genes were affected by the low-temperature stress in both varieties, with SoCBL3 being affected the most, followed by SoCBL5, while SoCBL1 and SoCBL9 were less affected, which indicates that the role of the $C B L$ genes was consistent regardless of varieties under low-temperature stress.

\section{Discussion}

Cold is a detrimental abiotic stress to the growth of sugarcane, decreasing the crop yield during the cold season and affecting the income from crop production $[25,26]$. The cold resistance of sugarcane is already known to be associated with morphological and physiological characteristics such as leaf thickness, vesicular cell area, thick-walled vascular bundle tissue thickness, and electrolyte extravasation rates [27]. In addition, cold stress leads to increased peroxidation of the leaf membrane, and increased soluble sugar, 
proline, and MDA content, but decreased chlorophyll content in sugarcane [28,29]. At a molecular level, studies revealed that cold stress influenced the expression of several genes in sugarcane, including those identified by bioinformatic analyses to be involved in calcium metabolism [30,31]. Similar results were reported in other plant species [32-34].

Calcium is a critical messenger in many adaptation and developmental processes, and is detected and transmitted by a variety of calcium sensor molecules to elicit different responses in plants. The calcineurin B-like protein (CBL) family serves as a unique group of calcium sensors by sensing calcium signals with the help of a family of protein kinases (CIPKs). The five SoCBL genes (SoCBL1, SoCBL3, SoCBL5, SoCBL6, and SoCBL9) were cloned in the present study. The amino sequences and functional domains were analyzed. The structures of the five CBL proteins were very conserved and identical (Table 3). All five proteins contained three EF-hand domains, whereas it was reported that the CBL protein typically contains four highly conserved EF-hand domains [35]. These two domains might be involved because the EF-hand domain binds $\mathrm{Ca}^{2+}$ via the loop structure to cause protein conformation changes, thereby activating the protein function and then regulating plant responses to various stresses with the help of multiple signal transduction systems [9]. In addition, it was found that the sugarcane SoCBL proteins contain various putative phosphorylation sites, such as casein kinase II and protein kinase C, especially in SoCBL3, SoCBL5, and SoCBL6, which also contain putative cAMP- and cGMP-dependent protein kinase phosphorylation sites. When plants undergo environmental changes, the $\mathrm{Ca}^{2+}$ receptor itself does not perform an enzymatic activity, but its activity is activated when binding $\mathrm{Ca}^{2+}$ combined with the $\mathrm{Ca}^{2+}$ released by the plant itself to activate the $\mathrm{Ca}^{2+}$-regulated target enzyme activity, subsequently by phosphorylation and a series of intermolecular interactions of kinases, regulating the expression changes of specific genes to enhance stress resistance [36]. It was shown that this EF-hand domain of CBL plays a role in salt tolerance $[37,38]$. However, further investigation is needed to investigate whether it has the same effect under low-temperature stress.

Numerous studies have shown that CBL plays an important regulatory role in plants under many environmental stresses, such as high salt and low temperature [39], but few studies have examined the $C B L$ genes in sugarcane $[19,20,22,40]$. Five $C B L$ genes were cloned (GenBank accession \#KC800815, KC800816, KC800817, KC800818, and KC800819) from the sugarcane cultivar GT28 by Zhang in 2013 [40]. The CBL members in sugarcane appear to be involved in the response to numerous chemical stresses, such as salicylic acid, methyl jasmonate, hydrogen peroxide, polyethylene glycol, salt, and copper chloride [22]. The overexpression of CBLs in Nicotiana benthamiana also increased the tobacco resistance to the Ralstonia solanacearum pathogen [22]. Ling et al. [20] also showed that ScCBL1 and ScCBL6 were involved in low-potassium, drought, and salt stresses. In this research, the expression analysis of five sugarcane $C B L$ genes under low-temperature stress was carried out, and it was found that the expression of SoCBL1, SoCBL5, SoCBL6, and SoCBL9 increased under low-temperature stress, indicating that these genes play an important role in plant signal transduction under low-temperature stress. Because the basic function of $C B L$ is to sense the changes in calcium concentration, the expression of sugarcane $C B L$ genes probably increased, triggered by the calcium concentration, suggesting that these genes can respond to the changes in calcium concentration [41]. Therefore, it is speculated that the $C B L$ genes in sugarcane might participate in the response to low-temperature stress. Nevertheless, the expression of SoCBL3 declined under low-temperature stress, suggesting that the regulation mechanism of the $C B L$ family genes is different under different types of temperature stress.

\section{Conclusions}

A CBL-CIPK signaling pathway is a complex system. In order to make clear how the sugarcane $C B L$ genes interact with specific proteins to activate the downstream genes under low-temperature stress, a comprehensive analysis of genes was needed concerning the function of sugarcane CBL and CIPK. The five sugarcane CBL genes cloned in this 
study showed a certain response to low-temperature stress, but, due to different gene functions, the defense pathways involved in the response to low-temperature stress might be different, which would provide an important molecular basis for strengthening sugarcane against low-temperature stress and other abiotic stresses, and could be referred to by subsequent research.

Author Contributions: Conceptualization, B.-Q.Z. and X.-P.S.; software, X.-Q.Z.; validation, Y.-R.L.; formal analysis, B.-Q.Z.; investigation, B.-Q.Z., Y.-J.L. and S.Z.; data curation, B.-Q.Z., Y.-X.H., S.Z. and C.-F.Y.; writing-review and editing, B.-Q.Z. and X.-P.S.; supervision, L.-T.Y.; project administration, X.H. and Y.-R.L. All authors have read and agreed to the published version of the manuscript.

Funding: This research was co-supported by the National R\&D Program of China (2018YFD1000500 2019YFD1000500), National Natural Science Foundation of China $(31760415,31660356,31901594)$, Guangxi Science and Technology Major Project (GK AA17202042-1, GK AB16380126), Guangxi Academy of Agricultural Sciences Science and Technology Development Fund Project (GNK2018JZ16, GNK2018JZ31, GNK2017JZ19), Guangxi Science and Technology Base and Talent Special (GK AD17195100), Guangxi "Bagui Scholars" Special Project (2013-03), and National Modern Agricultural Production Technology System Guangxi Sugarcane Innovation Team Project (nycytxgxcxtd-2021-03-01).

Institutional Review Board Statement: Not applicable.

Informed Consent Statement: Not applicable.

Conflicts of Interest: The authors declare no conflict of interest.

\section{References}

1. Xiong, L.; Schumaker, K.S.; Zhu, J.-K. Cell Signaling during Cold, Drought, and Salt Stress. Plant Cell 2002, 14 (Suppl. 1), S165-S183. [CrossRef] [PubMed]

2. Sanders, D.; Pelloux, J.; Brownlee, C.; Harper, J.F. Calcium at the Crossroads of Signaling. Plant Cell 2002, 14, S401-S417. [CrossRef] [PubMed]

3. Dodd, A.N.; Kudla, J.; Sanders, D. The language of calcium signaling. Annu. Rev. Plant Biol. 2010, 61, 593-620. [CrossRef] [PubMed]

4. Liu, J.; Zhu, J.-K. A Calcium Sensor Homolog Required for Plant Salt Tolerance. Science 1998, 280, 1943-1945. [CrossRef] [PubMed]

5. Kudla, J.; Xu, Q.; Harter, K.; Gruissem, W.; Luan, S. Genes for calcineurin B-like proteins in Arabidopsis are differentially regulated by stress signals. Proc. Natl. Acad. Sci. USA 1999, 96, 4718-4723. [CrossRef] [PubMed]

6. Harmon, A.C.; Gribskov, M.; Harper, J.F. CDPKs-A kinase for every Ca ${ }^{2+}$ signal? Trends Plant Sci. 2000, 5, 154-159. [CrossRef]

7. Snedden, W.A.; Fromm, H. Calmodulin as a versatile calcium signal transducer in plants. New Phytol. 2001, 151, 35-66. [CrossRef]

8. Batistič, O.; Kudla, J. Plant calcineurin B-like proteins and their interacting protein kinases. Biochim. Biophys. Acta 2009, 1793, 985-992. [CrossRef]

9. Kolukisaoglu, Ü.; Weinl, S.; Blazevic, D.; Batistic, O.; Kudla, J. Calcium Sensors and Their Interacting Protein Kinases: Genomics of the Arabidopsis and Rice CBL-CIPK Signaling Networks. Plant Physiol. 2004, 134, 43-58. [CrossRef]

10. Luan, S.; Kudla, J.; Rodriguez-Concepcion, M.; Yalovsky, S.; Gruissem, W. Calmodulins and Calcineurin B-like Proteins. Plant Cell 2002, 14, S389-S400. [CrossRef]

11. Luan, S. The CBL-CIPK network in plant calcium signaling. Trends Plant Sci. 2009, 14, 37-42. [CrossRef] [PubMed]

12. Ishitani, M.; Liu, J.; Halfter, U.; Kim, C.-S.; Shi, W.; Zhu, J.-K. SOS3 Function in Plant Salt Tolerance Requires N-Myristoylation and Calcium Binding. Plant Cell 2000, 12, 1667-1677. [CrossRef] [PubMed]

13. Cheong, Y.H.; Kim, K.-N.; Pandey, G.K.; Gupta, R.; Grant, J.J.; Luan, S. CBL1, a Calcium Sensor That Differentially Regulates Salt, Drought, and Cold Responses in Arabidopsis. Plant Cell 2003, 15, 1833-1845. [CrossRef] [PubMed]

14. Cheong, Y.H.; Sung, S.J.; Kim, B.-G.; Pandey, G.K.; Cho, J.-S.; Kim, K.-N.; Luan, S. Constitutive overexpression of the calcium sensor CBL5 confers osmotic or drought stress tolerance in Arabidopsis. Mol. Cells 2010, 29, 159-165. [CrossRef]

15. Pandey, G.K.; Cheong, Y.H.; Kim, K.-N.; Grant, J.J.; Li, L.; Hung, W.; D'Angelo, C.; Weinl, S.; Kudla, J.; Luan, S. The Calcium Sensor Calcineurin B-Like 9 Modulates Abscisic Acid Sensitivity and Biosynthesis in Arabidopsis. Plant Cell 2004, 16, 1912-1924. [CrossRef]

16. Yoon, S.; Park, J.; Ryu, M.; Yoon, I.S.; Kim, K.-N. Calcineurin B-like proteins in rice can bind with calcium ion and associate with the Arabidopsis CIPK family members. Plant Sci. 2009, 177, 577-583. [CrossRef]

17. Mahajan, S.; Sopory, S.K.; Tuteja, N. Cloning and characterization of CBL-CIPK signalling components from a legume (Pisum sativum). FEBS J. 2006, 273, 907-925. [CrossRef]

18. Zhao, J.F.; Yu, A.L.; Tian, G.; Du, Y.W.; Guo, E.H.; Diao, X.M. Identification of CBL genes from foxtail millet (Setaria italica L. Beauv) and its expression under drought and salt stresses. Acta Agron. Sin. 2013, 39, 360. [CrossRef] 
19. Farani, T.; Gentile, A.; Tavares, R.; Ribeiro, C.; Menossi, M. Characterization of a protein-protein interaction network of the CBL-interacting protein kinase 8 from sugarcane. Genet. Mol. Res. 2015, 14, 483-491. [CrossRef]

20. Ling, Q.; Zeng, Q.; Wu, J.; Hu, F.; Li, Q.; Qi, Y. Analysis of CBL1 and CBL6 gene expression in sugarcane under abiotic stress. Mol. Plant Breed. 2018, 16, 377-385. [CrossRef]

21. Ling, Q.P.; Wu, J.Y.; Yang, Z.D.; Zhou, W.L.; Huang, Y.; Li, Q.W.; Zeng, Q.Y. Cloning and Expression Characteristic Analysis of SsCBL4 gene from Sugarcane (Saccharum spp.). J. Agric. Bio. 2019, 27, 1351-1359.

22. Su, W.; Huang, L.; Ling, H.; Mao, H.; Huang, N.; Su, Y.; Ren, Y.; Wang, D.; Xu, L.; Muhammad, K.; et al. Sugarcane calcineurin B-like (CBL) genes play important but versatile roles in regulation of responses to biotic and abiotic stresses. Sci. Rep. 2020, 10, 167. [CrossRef] [PubMed]

23. Albrecht, V.; Weinl, S.; Blazevic, D.; D’Angelo, C.; Batistic, O.; Kolukisaoglu, Ü.; Bock, R.; Schulz, B.; Harter, K.; Kudla, J. The calcium sensor CBL1 integrates plant responses to abiotic stresses. Plant J. 2003, 36, 457-470. [CrossRef] [PubMed]

24. Sánchez-Barrena, M.J.; Martinez-Ripoll, M.; Albert, A. Structural Biology of a Major Signaling Network that Regulates Plant Abiotic Stress: The CBL-CIPK Mediated Pathway. Int. J. Mol. Sci. 2013, 14, 5734-5749. [CrossRef] [PubMed]

25. Knight, L.; Riggs, W. Nourishing urbanism: A case for a new urban paradigm. Int. J. Agric. Sustain. 2010, 8, 116-126. [CrossRef]

26. Pang, X.; Zhu, P.; Zhou, Q.; Huang, Q.; Tan, Q.; Chun, L. Research progress on sugarcane response to cold stress. Guizhou Agric. Sci. 2015, 43, 39-43.

27. Zhu, P.; Pang, X.; Tan, Q.; Liang, C.; Yan, L.; Zhou, Q. Effects of chilling on photosynthesis and photosynthetic pigment contents in leaves of different sugarcane varieties. Chin. J. Trop. Crop. 2019, 40, 51-57.

28. Ding, C.; Yang, Q.; Li, F.; Weifu, L. Effect of cold stress on the content of free-proline in leaf of Saccharum spontaneum L. and sclerostachya (II). J. Anhui Agric. Sci. 2006, 34, 30-33. [CrossRef]

29. Wang, H.; Jiao, X.; Kong, X.; Hamera, S.; Wu, Y.; Chen, X.; Fang, R.; Yan, Y. A Signaling Cascade from miR444 to RDR1 in Rice Antiviral RNA Silencing Pathway. Plant Physiol. 2016, 170, 2365-2377. [CrossRef]

30. Huang, X.; Liang, Y.; Zhang, B.; Song, X.; Li, Y.; Qin, Z.; Li, D.; Chen, R.; Zhou, Z.; Deng, Y.; et al. Integration of Transcriptional and Post-transcriptional Analysis Revealed the Early Response Mechanism of Sugarcane to Cold Stress. Front. Genet. 2021, 11, 1715. [CrossRef]

31. Yang, Y.; Zhang, X.; Su, Y.; Zou, J.; Wang, Z.; Xu, L.; Que, Y. miRNA alteration is an important mechanism in sugarcane response to low-temperature environment. BMC Genom. 2017, 18, 833. [CrossRef] [PubMed]

32. Peng, X.; Wu, Q.; Teng, L.; Tang, F.; Pi, Z.; Shen, S. Transcriptional regulation of the paper mulberry under cold stress as revealed by a comprehensive analysis of transcription factors. BMC Plant Biol. 2015, 15, 43. [CrossRef] [PubMed]

33. Li, Q.; Byrns, B.; Badawi, M.A.; Diallo, A.B.; Danyluk, J.; Sarhan, F.; Laudencia-Chingcuanco, D.; Zou, J.; Fowler, D.B. Transcriptomic Insights into Phenological Development and Cold Tolerance of Wheat Grown in the Field. Plant Physiol. 2017, 176, 2376-2394. [CrossRef] [PubMed]

34. Shi, Y.; Ding, Y.; Yang, S. Molecular Regulation of CBF Signaling in Cold Acclimation. Trends Plant Sci. 2018, $23,623-637$. [CrossRef]

35. Batistic, O.; Kudla, J. Integration and channeling of calcium signaling through the CBL calcium sensor/CIPK protein kinase network. Planta 2004, 219, 915-924. [CrossRef]

36. Fuglsang, A.T.; Guo, Y.; Cuin, T.A.; Qiu, Q.; Song, C.; Kristiansen, K.A.; Bych, K.; Schulz, A.; Shabala, S.; Schumaker, K.S.; et al. Arabidopsis Protein Kinase PKS5 Inhibits the Plasma Membrane H+-ATPase by Preventing Interaction with 14-3-3 Protein. Plant Cell 2007, 19, 1617-1634. [CrossRef]

37. Ma, X.; Li, Q.-H.; Yu, Y.-N.; Qiao, Y.-M.; Haq, S.; Gong, Z.-H. The CBL-CIPK Pathway in Plant Response to Stress Signals. Int. J. Mol. Sci. 2020, 21, 5668. [CrossRef]

38. Chen, P.; Yang, J.; Mei, Q.; Liu, H.; Cheng, Y.; Ma, F.; Mao, K. Genome-Wide Analysis of the Apple CBL Family Reveals That Mdcbl10.1 Functions Positively in Modulating Apple Salt Tolerance. Int. J. Mol. Sci. 2021, 22, 12430. [CrossRef]

39. Jiang, X.-S.; Wassif, C.; Backlund, P.S.; Song, L.; Holtzclaw, L.; Li, Z.; Yergey, A.L.; Porter, F.D. Activation of Rho GTPases in Smith-Lemli-Opitz syndrome: Pathophysiological and clinical implications. Hum. Mol. Genet. 2010, 19, 1347-1357. [CrossRef]

40. Zhang, B.Q. Study on the Physiological and Biochemical Characteristics and Differentially Expressed Proteome during Late Growth Stage of Sugarcane under Cold Stress. Ph.D. Thesis, Guangxi University, Nanning, China, 2013.

41. Li, H.; Cong, Y.C.; Chang, Y.; Lin, J.; Sheng, B.L. Isolation of a calcineurin b-like protein gene PbCBL2 from Pyrus betulaefolia and preliminary study of gene function. Acta Hortic. Sin. 2013, 40, 1445-1455. 